\title{
Structural alterations in a type IV pilus subunit protein result in concurrent defects in multicellular behaviour and adherence to host tissue
}

\author{
Hae-Sun Moon Park, ${ }^{1 \dagger}$ Matthew Wolfgang, ${ }^{1 \ddagger}$ Jos P. M. \\ van Putten, ${ }^{2 \S}$ David Dorward, ${ }^{3}$ Stanley F. Hayes ${ }^{3}$ and \\ Michael Koomey ${ }^{1,4 *}$ \\ ${ }^{1}$ Department of Microbiology and Immunology, University \\ of Michigan Medical School, Ann Arbor, MI 48109, USA. \\ ${ }^{2}$ Laboratory of Microbial Structure and Function, and \\ ${ }^{3}$ Microscopy Branch, Rocky Mountain Laboratories, \\ NIAID, NIH, Hamilton, MN, USA. \\ ${ }^{4}$ Biotechnology Centre of Oslo and Department of \\ Microbiology, University of Oslo, 0316 Oslo, Norway.
}

\section{Summary}

The ability of bacteria to establish complex communities on surfaces is believed to require both bacterial-substratum and bacterial-bacterial interactions, and type IV pili appear to play a critical but incompletely defined role in both these processes. Using the human pathogen Neisseria gonorrhoeae, spontaneous mutants defective in bacterial selfaggregative behaviour but quantitatively unaltered in pilus fibre expression were isolated by a unique selective scheme. The mutants, carrying single amino acid substitutions within the conserved aminoterminal domain of the pilus fibre subunit, were reduced in the ability to adhere to a human epithelial cell line. Co-expression of the altered alleles in the context of a wild-type pilE gene confirmed that they were dominant negative with respect to aggregation and human cell adherence. Strains expressing two copies of the altered alleles produced twice as much purifiable pili but retained the aggregative and adherence defects. Finally, the defects in aggregative behaviour and adherence of each of the mutants were suppressed by a loss-of-function mutation in the twitching motility gene pilT. The correlations between self-aggregation and the net capacity of the microbial population to adhere efficiently demonstrates

Accepted 18 July, 2001. *For correspondence. E-mail johnk@ biotek.uio.no; Tel. (+47) 22840 511; Fax (+47) 22840 501. Present addresses: 'Department of Microbiology, University of Minnesota, Medical School, Minneapolis, MN 55455, USA. ${ }^{\ddagger}$ Department of Microbiology and Molecular Genetics, Harvard Medical School Boston, MA 02115, USA. §Department of Bacteriology, Institute of Infectious Diseases and Immunology, University of Utrecht, NL-3584 CL Utrecht, The Netherlands. the potential significance of bacterial cell-cell interactions to colonization.

\section{Introduction}

In most host-parasite interactions, microbial attachment involves specific interactions between adhesins and host receptor molecules. Proteinaceous adhesins can be displayed on the bacterial surface as monomers, simple oligomeric structures or components of supramolecular fibres known as pili or fimbriae (Hultgren et al., 1993). Type IV pili (Tfp) are a unique class of multifunctional pili defined by their shared structural, biochemical, antigenic and morphological features. Tfp are expressed by Gramnegative bacteria of medical, environmental and industrial importance (Ottow, 1975). Neisseria gonorrhoeae, the aetiological agent of gonorrhoea, has proved to be a particularly good system in which to study Tfp biology. This situation stems from the amenability of the organism to genetic manipulation, the availability of the complete genome sequence and the fact that these pili play a critical role in human disease by acting as an essential factor in the colonization of human mucosal surfaces. The capacity of gonococcal Tfp to adhere to human epithelial cells appears to involve recognition of the cell surface receptor CD46 (membrane cofactor protein) (Kallstrom et al., 1997) mediated by the PilC protein, which co-purifies with Tfp and has been co-localized to Tfp fibres by immunolabelling (Scheuerpflug et al., 1999). In addition to its role in human cell ligand recognition, gonococcal Tfp expression has been linked to a form of cellular interaction termed autoagglutination, based on the observations that nonpiliated strains or strains expressing reduced levels of pili lack this property. Autoagglutination of gonococcal cells has been proposed to result from the capacity of Tfp to form thick branched structures creating a fibrous network tethering cells to one another (Todd et al., 1984). The property of Tfp-associated bacterial aggregation is also seen in other species, notably Neisseria meningitidis (Marceau et al., 1995), the aetiological agent of meningitis, Vibrio cholerae (Taylor et al., 1987), enteropathogenic strains of Escherichia coli (EPEC) (Vuopio-Varkila and Schoolnik, 1991), the plant pathogen Xanthomonas campestris pv. vesicatora (Ojanen-Reuhs et al., 1997) and the soil microbe Myxococcus xanthus ( $\mathrm{Wu}$ et al., 
1997). In all but the last case, in vitro studies have shown that Tfp-associated self-aggregation promotes adherence in the form of microcolonies, which has been termed the localized adherence phenotype.

Gonococcal Tfp are also required for a novel mode of flagella-independent cell movement known as twitching motility (Henrichsen, 1983), which is also seen in Pseudomonas aeruginosa (Whitchurch et al., 1991), M. xanthus (Wu et al., 1997), in which it is manifest as social gliding motility, and EPEC strains (Bieber et al., 1998), in which it is demonstrated as aggregation dispersal. Although the exact role of Tfp in this phenomenon is unknown, mutations in the highly conserved pilT-like genes encoding members of the AAA protein family (Lessl and Lanka, 1994) lead to piliated but non-motile and hyperaggregated phenotypes in all these species. Mutations of this type in EPEC strains are associated with increased epithelial cell adherence in vitro (Anantha et al., 1998), consistent with the notion that bacterial selfaggregation mediated by Tfp contributes to host cell adherence. In the absence of quantitative data of Tfp levels, however, increased adherence may result from higher levels of organelle expression, which has in fact been claimed for pilT mutants in $P$. aeruginosa (Whitchurch et al., 1991). Interpretations of the EPEC findings are also clouded by the basic lack of knowledge of a Tfpassociated adhesin in that system whose expression might be altered in the background examined. The lack of well-characterized mutants in which self-aggregation has been specifically dissociated from Tfp expression has therefore made it difficult to establish a causal rather than a correlative association between aggregation and adherence.

In this paper, we report the isolation of gonococcal mutants defective in cell-cell aggregative behaviour, which are quantitatively unaltered in Tfp fibre expression. Independently derived mutants each carried single amino acid substitutions within the conserved amino-terminal domain of PilE, the pilus fibre subunit, and were found to be uniformly deficient in the ability to adhere to a human epithelial cell line. Direct examination of the patterns of adherence displayed by the mutants revealed a specific defect in microcolony formation but not in binding of single diplococci to tissue. These adherence defects were manifest despite the fact that the PilC human tissue adhesin remained associated with purified fibres. Coexpression of a wild-type pilE gene in the context of the altered pilE alleles confirmed that they corresponded to dominant-negative mutations with respect to cell-cell aggregation and human cell adherence. Strains constructed to express two copies of the altered alleles produced twice as much purifiable pili but retained the aggregative and adherence defects, ruling out a quantitative defect in organelle expression as an explanation for the altered phenotypes. Finally, suppression of the cellcell aggregative defect in all three cases correlated with restoration of high-level adherence for the human epithelial cell line. These findings establish a strong correlation between multicellular aggregative behaviour and the net proclivity of a microbial population to adhere efficiently to host tissue.

\section{Results}

Isolation and characterization of non-aggregating, piliated mutants resulting from pilE mutations

This study was initially undertaken in an effort to isolate unique Tfp biogenesis mutants. In wild-type, piliated gonococcal strains, non-aggregating $\left(\mathrm{Agg}^{-}\right)$variants arise at high frequencies via gene conversion-like recombinational events between pilE, the pilin subunit gene, and multiple, incomplete gene copies, termed pilS alleles, as a subset of events that leads to Tfp antigenic variation (Zhang et al., 1992). These non-productive rearrangements result in pilE missense, nonsense, frameshift and deletion mutations and, most often, these variants fail to express or express reduced levels of Tfp (Bergstrom et al., 1986). Disruption of pilin gene recombination by the introduction of $\operatorname{rec} A$ null alleles reduces the frequencies with which $\mathrm{Agg}^{-}$variants arise 1000-fold (Koomey et al., 1987). Even in recA strains, however, classical frameshift, missense and deletion mutants in pilE account for the majority of mutants lacking Tfp. In an attempt to isolate mutants altered at other loci encoding Tfp biogenesis factors, we introduced the recA6 null allele into a laboratory variant that carries two complete and identical copies of pilE, with the expectation that mutations in single-copy biogenesis genes would predominate over inactivating mutations in both pilE alleles. This strain was highly stable with regard to Tfp expression; however, prolonged incubation periods of growth $(>72 \mathrm{~h}$ ) on solid media yielded $\mathrm{Agg}^{-}$mutants arising as sectored domains in colonies. When isolated in pure culture, these mutants were indistinguishable in their aggregation defect from control non-piliated mutants. Surprisingly, all such mutants retained Tfp expression as seen by electron microscopy and organelle purification techniques (data not shown).

To assess the basis for these mutants, their genomic DNAs were used to transform a recombination-proficient strain with two active pilE genes, and $\mathrm{Agg}^{-}$recombinants were selected. Unlike the highly stable $\mathrm{Agg}^{-}$phenotypes found in the $\operatorname{RecA}^{-}$parental strains, the recombinationproficient derivatives spawned $\mathrm{Agg}^{+}$revertants at frequencies of $10^{-2}-10^{-3}$. As the differential effect of homologous recombination on phenotype stability could be accounted for most readily by mutations in one of the two pilE genes, the DNA sequences for both pilin alleles in 
four independently arising mutants was determined. In one case, a chain-terminating mutation in the codon for W119 of one gene had occurred. Further analysis showed that this strain had reduced levels of Tfp compared with an isogenic, single pilE gene-expressing strain, indicating that the truncated pilin subunit interfered with assembly of the unaltered one and that the aggregation defect reflected a diminution in fibre expression (data not shown).

The remaining three mutants each carried single base mutations in one of the two genes altering residues within the first 20 residues of PilE. These included substitutions of threonine for isoleucine at position +4 (14T), methionine for valine at +9 (V9M) and threonine for alanine at +20 (A20T). The residues altered are conserved among the type IV structural subunits, although A20 is less conserved among the type IVb class of pilins found in $V$. cholerae and EPEC strains (Fig. 1A) (Giron et al., 1994). Besides their co-localization within the highly conserved amino-terminus, the most obvious feature shared by prepilins carrying these alterations was a slight reduction in the hydrophobicity of this domain as modelled by the algorithm of Kyte and Doolittle (1982) (data not shown).

\section{Pilin mutations lead to intrinsic defects in cell-cell} aggregation and epithelial cell adherence independently of quantitative alterations in Tfp expression

Given the stringent selection scheme, it was formally possible that mutations unlinked to pilE may have arisen to account for the $\mathrm{Agg}^{-}$phenotype. It was also unclear whether the pilins encoded by the missense alleles were assembly proficient. We reconstructed each of the mutations in a cloned pilE gene and introduced the mutations into a strain with a single pilE locus using a nonselective transformation protocol (Gunn and Stein, 1996). Strains expressing pilE mutations known to preclude Tfp

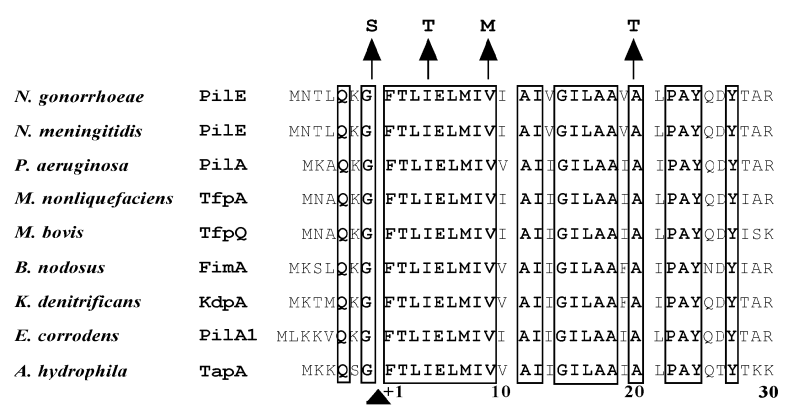

Fig. 1. Amino acid residues altered in spontaneous pilE missense mutants and predicted effects on hydrophobicity of the N-terminal domain. Alignment of the conserved $\mathrm{N}$-terminal region of known type IV prepilin was done using PILEUP. Identical residues are shown in bold and boxed. Arrows indicate locations of a single amino acid substitution in $N$. gonorrhoeae mutants. A triangle indicates the prepilin peptidase processing site carboxy-terminal to the conserved glycine, and numbering across the bottom indicates the amino acid position in the mature pilin subunit. biogenesis (a glycine to serine substitution at position -1 ; G-1S) (Koomey et al., 1991) and a tryptophan to serine substitution at position 109 (W109S) (Zhang et al., 1992) were also constructed to serve as negative controls. In each case, DNA sequencing was used to ensure that the pilE loci were unaltered save for the single base mutations. All strains were non-aggregating and were indistinguishable from one another in colony morphotypes and their patterns of growth in liquid cultures as dispersed cells (data not shown). Immunoblotting of whole-cell lysates using PilE antiserum confirmed that PilE was expressed at equivalent levels and showed, in the case of the G-1S and W109S mutants, that it was also present in a faster migrating form lacking the first 39 residues of mature PilE (Fig. 2A). This altered form of PilE, termed S-pilin, is seen in mutants blocked or deficient in Tfp biogenesis and appears to represent a default pathway of pilin degradation (Koomey et al., 1991). Quantitative pilus fibre purification was used to examine the relative levels of Tfp as shown in Fig. 2B. Tfp were not recoverable from the two non-piliated control strains, whereas no differences in Tfp yields were discernible among the others. In addition, the levels of copurifying PilC (the Tfp-associated human epithelial cell adhesin) in the fractions were indistinguishable from one another (Fig. 2C), and silver staining of gels of these Tfp preparations run in parallel failed to reveal any differences in other proteins (data not shown). Strains expressing the $\mathrm{N}$-terminal missense pilins expressed amounts of Tfp fibres in quantities similar to that found for the wild-type strain (Fig. 3). Tfp fibres in the V9M and A20T strains were distinct in that they had a wavy or crinkly appearance in the former case and a rigid and highly laterally aggregated appearance in the latter. The A20T fibres also appeared to be narrower in diameter than the others.

Examination of these strains after interaction with the human ME180 epithelial cell line showed significant defects in bacterial adherence for all the mutants. However, in contrast to the non-piliated mutants, which had more than a 20 -fold reduction in adherence relative to the wild-type strain, the piliated but non-aggregating strains had similar levels of adherence, which were approximately fivefold reduced (Fig.4). Microscopic examination of the patterns of adherence showed two forms of bacterial-epithelial cell interaction, one exemplified by the retention of microcolonies containing large numbers of diplococci analogous to the localized adherence phenotype (seen only in the wild-type, aggregating strain) and a second involving a diffuse adherence phenotype with single diplococci or small clusters of a few diplococci (seen for all the piliated strains) (Fig.5). The quantitative differences in adherence of the aggregating and non-aggregating strains therefore paralleled the presence or absence of localized adherence. Taken together, these results indicate that the amino acid 


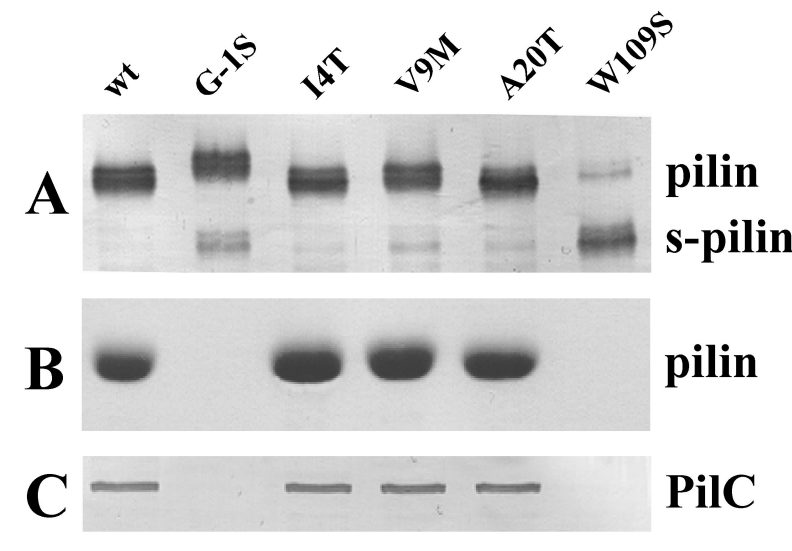

Fig. 2. PilE, Tfp and Tfp-associated PilC expression in PilE missense mutants. Immunoblot analysis of gonococcal whole-cell lysates (A), along with Coomassie-stained SDS-PAGE gels showing the relative amounts of pilin (B) and PilC (C) in purified Tfp preparations. Amounts of sample loaded were normalized to one another based on total amounts of protein in whole-cell lysates (A) or in whole-cell fractions after shear preparation of Tfp (B and C).

substitutions in the mature $\mathrm{N}$-terminus of PilE lead to defects in cell-cell aggregation and human cell adherence that cannot be accounted for by simple quantitative reductions in levels of Tfp expression.

\section{Pilin mutations are dominant negative with respect to} aggregation and epithelial cell adherence

In view of the implication that pilE alleles isolated in the original screening procedure were dominant-negative mutations with respect to cell-cell aggregation, it was of interest to confirm this possibility in a clean genetic background. Therefore, a complete wild-type pilE allele was introduced into the iga locus (encoding IgA1 protease) of the strains expressing the altered pilE alleles from the normal locus. As a control, the wild-type pilin allele ( $p i l E_{\mathrm{wt}}$ ) was introduced at the ectopic site (iga) in a strain conditionally defective in pilE expression from its endogenous locus. This strain, expressing only the ectopic gene, was indistinguishable from the wild-type strain in PilE and Tfp expression levels (Wolfgang et al., 2000), cell-cell aggregation and ME180 human cell adherence (data not shown). Expression of the ectopic gene in the wild-type background increased both ME180 cell adherence and the yield of purifiable $\mathrm{Tfp}$ at least twofold (Fig. 6A) and showed a slight enhancement on cell-cell aggregation. Expression of the ectopic gene in the context of the other alleles also increased both ME180 cell adherence and the yield of purifiable Tfp twofold (Fig. 6B), but did not detectably alter the non-aggregating phenotype associated with the missense mutations (data not shown). The strain expressing wild-type PilE together with W109S pilin had levels of purifiable Tfp equivalent to the singlegene-copy strains but, surprisingly, was as deficient in cell-cell aggregation as the non-piliated strain expressing only the W109S pilin from which it was derived. In addition, this strain behaved like the other piliated but nonaggregating backgrounds in its quantitative adherence to the ME180 cells (Fig. 6A, lane 10). As seen previously, direct examination of the patterns of adherence to the human cells showed a strict correspondence in all cases between localized adherence, efficient binding and cellcell aggregation and, conversely, diffuse adherence, reduced binding and non-aggregation (data not shown). Moreover, these defects could not be ascribed to alterations in the levels of co-purifying PilC (Fig.6B). These findings show that each of the mutations altering residues within mature PilE are dominant negative with respect to aggregation and epithelial cell adherence.

\section{Defects in aggregation and epithelial cell adherence are not suppressed by overexpression of mutant pilins}

To test whether increased expression of the mutant pilins could overcome the defects in aggregative and adherence properties, the method of ectopic gene expression described above was used to construct strains carrying two identical pilE gene copies. As shown in Fig.7, increasing the gene copy number to two of each altered allele increased both ME180 cell adherence and the yield of purifiable Tfp approximately twofold. However, the increase in Tfp expression did not alter the nonaggregating status or diffuse pattern of ME180 cell adherence of the mutants (Table 1, data not shown). The results formally rule out the possibility that quantitative reduction in Tfp expression could account for defects in cell-cell aggregation and human cell adherence.

\section{Suppression of the defects in both cell-cell aggregation and epithelial cell adherence by a loss-of-function mutation in pilT, a twitching motility gene}

Loss-of-function mutations in the pilT genes of pathogenic Neisseria species and $M$. xanthus as well as in the related $b f p F$ gene of EPEC strains result in hyperaggregating phenotypes that are dependent on Tfp expression. These results suggest that the nucleotide-binding proteins required for twitching motility act in some manner as inhibitors of Tfp-associated aggregation. In order to test what contribution gonococcal PilT might have on the nonaggregating properties of the mutants isolated here, a transposon insertion mutation in pilT (Wolfgang et al., 1998) was crossed onto the genome of these strains. As documented previously, the wild-type strain with this mutation was hyperaggregating and deficient in twitching motility. A hyperaggregating and non-motile phenotype indistinguishable from that found for the wild-type, $\mathrm{PilT}^{-}$ strain was also exhibited by the 14T, V9M and A20T strains 


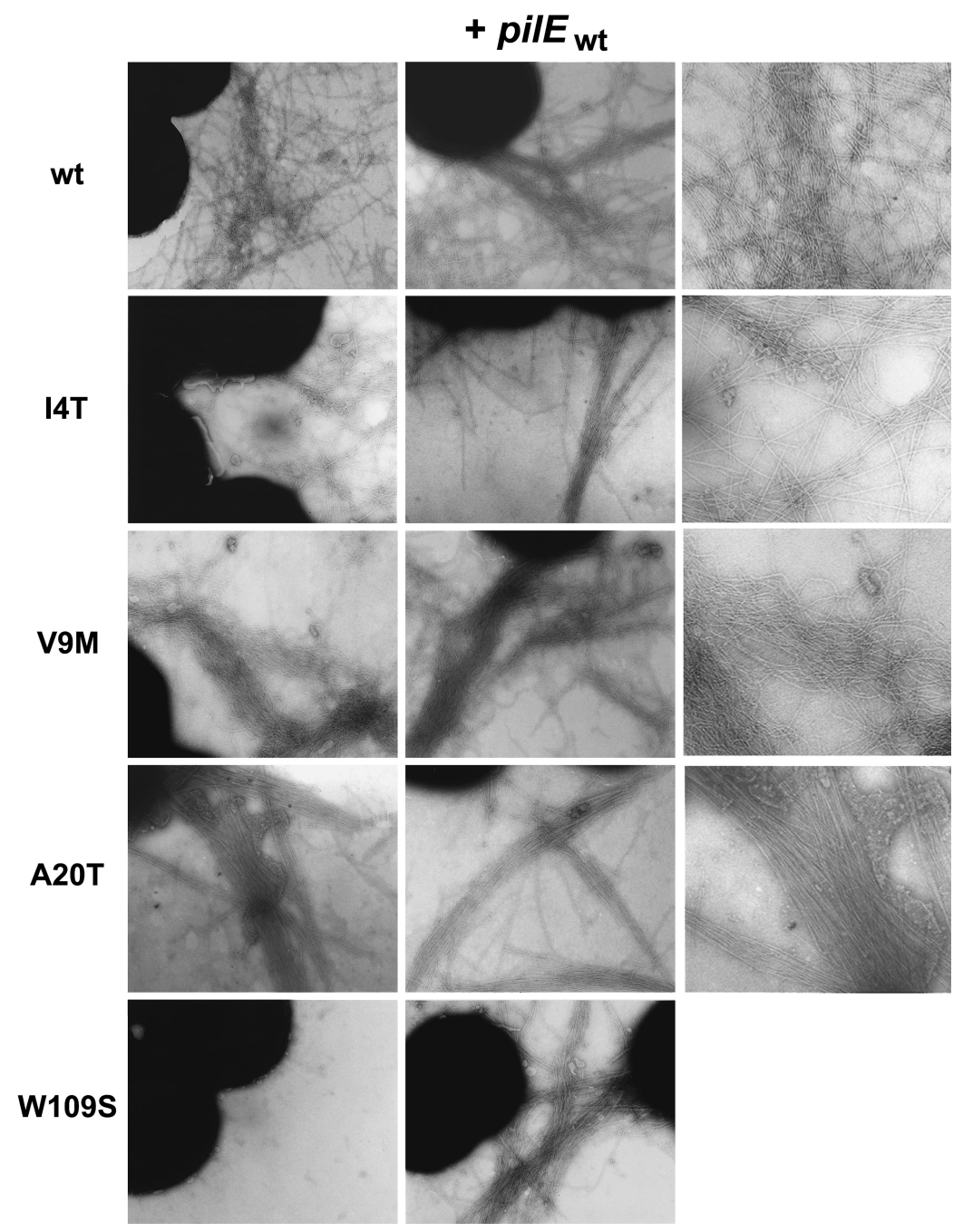

Fig. 3. Missense PilE polypeptides influence pilus fibre morphology. Transmission electron micrographs of strains expressing PilE missense polypeptides show qualitative differences in pilus fibre arrangement and morphology. Strains shown in the leftmost column are wt (N400), I4T (GE101), V9M (GE102), A20T (GE103) and W109S (GE104). Centre columns shows strains co-expressing the wild-type pilE allele, and strains shown are: wt, GE200 (pilE, iga::pilE); 14T, GE301 ( pilE 14 T, iga::pilE); V9M, GE302 ( pilE $\mathrm{V}_{\mathrm{VM}}$, iga::pilE); A20T, GE303 ( pilE $\mathrm{A}_{\mathrm{A} 20 \mathrm{~T}}$, iga::pilE); and W109S, GE304 (pilE $E_{\mathrm{W} 109 \mathrm{~S}}$ iga::pilE). All magnifications are $135000 \times$ save for the rightmost column, which shows $4 \times$ enlargements of areas found in photos in the leftmost columns.

carrying the pilT mutation (Table 1). The pilT gene and the pil gene immediately distal to it, which encodes a protein highly related to PilT, are expressed as a single transcriptional unit (H.-S. M. Park, M. Wolfgang, and M. Koomey, manuscript submitted). It was formally possible then that the suppression seen here related to the absence of PilU and not PilT. However, introduction of a pill transposon insertion mutation into these strains did not alter aggregation or any of the other Tfp-associated phenotypes in these backgrounds (data not shown). Therefore, PilT expression dramatically influences the aggregation defects in the pilin mutants. In contrast, the pilT mutation did not suppress the non-aggregating phenotype of the non-piliated W109S mutant, which is consistent with the evidence that Tfp expression is necessary for this property.

This same pilT mutation suppressed the non-aggregating phenotype of the heterodiploid strains simultaneously expressing both wild-type and I4T, V9M and A20T alleles. Similarly, the pilT mutation suppressed the aggregation defect in the heterodiploid strain expressing the W109S allele and the wild-type pilin gene.

The genetically defined strains in which bacterial aggregation was restored by the pilT mutation provided an opportunity to examine the relationship of gonococcal cell-cell interaction to human cell adherence. Figure $8 \mathrm{~A}$ shows that adherence for ME180 cells was dramatically increased in conjunction with restoration of aggregation in each instance, although yields of purifiable Tfp (Fig. 8B) and levels of associated PilC protein were unaltered (data not shown). This was also true for all the homodiploid as well as the heterodiploid strains (data not shown) including that expressing the W109S allele (Fig. 8B, lane 11). Microscopic examination of adherence using the pilin mutants revealed a dramatic shift from a diffuse pattern of adherence to a completely localized pattern, in which only large microcolonies were present. These findings are exemplified by the data from the A20T strains shown in Fig. $8 \mathrm{C}$ (centre and right). 


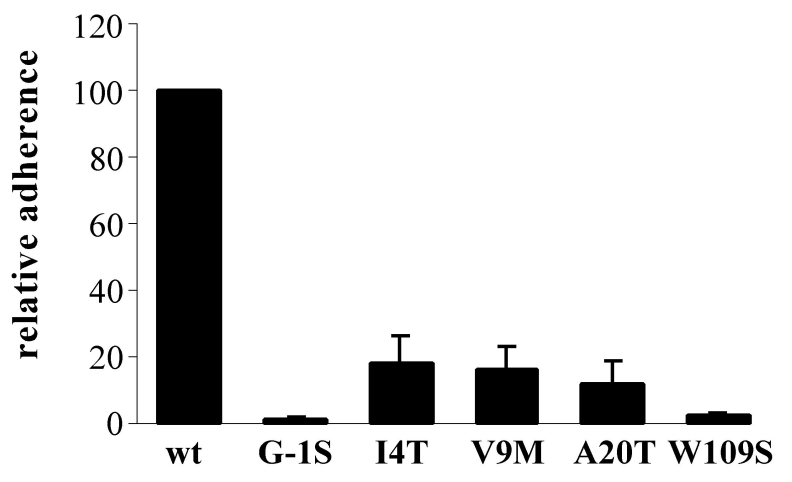

Fig. 4. PilE missense mutations influence levels of Tfp-mediated adherence for human ME180 cells. Quantification of gonococcal adherence is assessed by recovery of viable colony-forming units (cfu). The results are the average of three independent experiments, with error bars indicating the standard deviations, and are presented as a ratio of the values of the mutants versus the wild-type control in percentages.

Defects in Tfp-associated aggregation are associated with altered organization of fibres into higher ordered structures

As restoration of aggregation by loss of functional PilT in the mutants did not correlate with either qualitative changes in fibre morphology or lateral aggregation of fibres as seen in transmission electron microscopy (TEM; data not shown), the strains were examined by scanning electron microscopy (SEM) after sample preparation by a critical point drying method. These techniques have been used to demonstrate the organization of gonococcal Tfp fibres into rope-like bundles, which branch, subdivide and rejoin to form a lattice-like network that interconnects cells (Todd et al., 1984). These structures have been proposed to provide the basis for Tfp-associated aggregation by physically tethering cells to one another. As shown in Fig. 9, the wild-type strain had numerous, short fibrous structures intercalated between adjacent cells, which were absent from the non-piliated, W109S mutant. For the I4T and A20T mutants, the fibrous structures were wider in diameter and, instead of connecting adjacent cells in the colonies, they appeared to be more irregularly dispersed within the cell populations. In these two mutants then, it seemed that the finer, shorter structures in the wild type had coalesced into wider, elongated organelles. The structures in the V9M mutant were more similar in morphology to that seen for the wild-type strain, but the number of intercalating fibres was reduced. In all cases for the piliated, non-aggregating strains, it was difficult to see clearly the structures emanating directly from or contacting the cell surface and, in most instances, the structures seemed to simply lie on or across the cell surface.

Differences in surface structure abundance and morphology were less obvious in the pilE heterodiploid strains, although the structures on the wild-type diploid were wider in diameter than the others (Fig. 9, middle column). Nonetheless, it was still difficult to find clear examples of the structures emanating from the cell surface in the N-terminal altered, non-aggregating mutants. This was not the case, however, in the W109S heterodiploid, but cell size, morphology and tubular projections were distorted in this background.

Electron micrographs of the strains with the pilT mutation and hyperaggregating phenotype were remarkably similar to one another in surface structure abundance, morphology and orientation relative to the cells (Fig. 9, right column). In summing up the EM analyses, we conclude that the aggregation defects in the pilin mutants are a consequence of alterations in the organization of Tfp fibres into the tubular-like organelles and the role of these structures in tethering cells to one another.

\section{Discussion}

The recognition of specific receptors on mammalian tissue by microbial adhesin molecules represents the earliest event in colonization and the initiation of disease. Although multicellular aggregative behaviour is a common feature of mucosal pathogens and cell-cell aggregation is often associated with adhesin expression, the significance of these associations remains largely unknown. In addition to those species expressing Tfp, other adhesins that are associated with self-aggregative behaviour include the $M$ proteins of group A streptococci (Caparon et al., 1991), filamentous haemagglutinin in Bordetella pertussis (Menozzi et al., 1994), the YadA protein of Yersinia (Tamm et al., 1993) and Opa proteins of $N$. gonorrhoeae (Swanson, 1978). Recent evidence suggests that type 1 fimbriae of E. coli (Pratt and Kolter, 1998) and Salmonella typhimurium (Thankavel et al., 1999), which are unrelated to Tfp, also contribute to aggregative processes. Attempts to dissect the relative contributions of adhesins to bacterial-host cell interactions and aggregative behaviour have been complicated by the difficulties in isolating mutants specifically lacking one or the other traits without altering other parameters.

We isolated gonococcal mutants defective in Tfpassociated aggregation, which were quantitatively and qualitatively unaltered in Tfp fibre expression according to current standards. Examination of these mutants revealed a remarkably consistent level of defectiveness in adherence properties for human ME180 epithelial cells relative to isogenic, aggregating, wild-type cells. In the case of the $\mathrm{N}$-terminal missense mutants, the fivefold defect in adherence was seen not only in the context of the single gene mutations but also in the dominant-negative situation. Additionally, the same level of adherence defectiveness was seen for non-aggregating mutants expressing both the wild-type pilin and the W109S allele, 

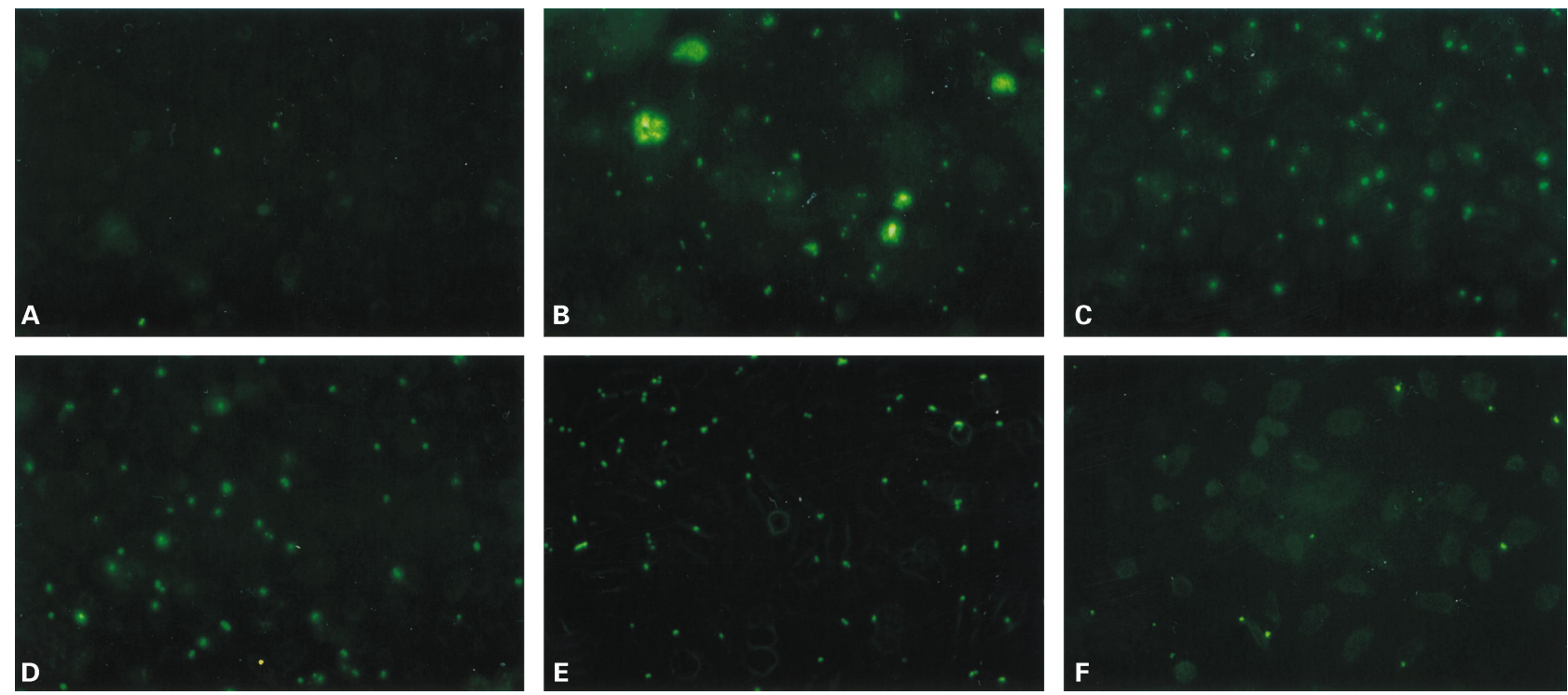

Fig. 5. PilE missense mutations influence the levels and patterns of Tfp-mediated adherence for human ME180 cells. The microscopic appearance of adherent gonococci detected using a fluorescein-tagged monoclonal antibody specific for the Por protein is shown. The fluorescence image was overlain onto the phase-contrast image to co-localize bacteria and ME180 cells. Strains shown are (A) G-1S (GE100); (B) wt (N400); (C) I4T (GE101); (D) V9M (GE102); (E) A20T (GE103); and (F) W109S (GE104).

although wild-type levels of Tfp were still expressed. These consistent results correlating aggregation and adherence proficiency were corroborated further by the simultaneous restoration of both traits in strains carrying an extragenic suppressor mutation. Finally, the most compelling evidence linking aggregation to more proficient adherence comes from the fact that the wild-type aggregating strains display both localized and diffuse patterns of adherence, whereas the non-aggregating strains uniformly exhibit only diffuse adherence patterns. Thus, the quantitative adherence defects are most simply explained by the absence of microcolony-forming organisms engaged in localized adherence. Conversely, increased aggregation associated with the pilT mutation heightened adherence proficiency, which was associated in each case with a shift from the diffuse or diffuse/ localized adherence behaviour to one that was entirely localized in character.

These data strongly suggest, but do not prove, that selfaggregation promotes net bacterial adherence. However, one can reasonably rule out two of the most likely alternative explanations for the findings. The first concern relates to the status of the Tfp-associated PilC protein, which is primarily, if not solely, responsible for epithelial cell-binding activity. PilC co-purifies with Tfp from all the mutants at levels equivalent to that seen in the aggregating strains with higher levels of adherence, thus apparently ruling out reductions in PilC levels as an explanation. It is formally possible that the manner in which PilC is displayed in association with Tfp fibres is altered such that its adhesive capacities are compromised. However, this scenario would seemingly have to be true for both the amino-terminal and the W109S mutants. Moreover, it is unclear why a loss of functional PilT would restore correct PilC orientation within the fibres of both classes of mutants. It could also be argued that PilC itself might not be properly activated or otherwise modified in these mutants. PilC purified from non-piliated strains of $N$. gonorrhoeae and from $E$. coli recombinants has been reported to retain human cell-binding activity, which can competitively block adherence of piliated $N$. gonorrhoeae, making it unlikely that it requires any unique modification for activity (Scheuerpflug et al., 1999). Therefore, alterations related to PilC in conjunction with the mutations do not appear to account for the observations.

A second possible set of explanations is that the integrity of Tfp fibres or their anchoring to the bacterial surface is compromised in the mutants. Although fibre morphology is altered in two of the mutants, the fibres themselves do not appear to be more brittle or susceptible to breakage in any of the mutants. In fact, on the contrary, fibres in the pilT mutant background that are associated with the highest levels of aggregation and adherence appear to be shorter and more fractured than their counterparts (data not shown). A defect in fibre anchoring could conceivably also diminish both aggregation and adherence. Issues relating to the association of Tfp with the bacterial cell surface are particularly difficult to address, as even in a wild-type background, TEM shows large numbers of fibres unassociated with the cells. It is important to note in this regard that each of the aggregation mutants described here is agglutinated by Tfp antisera, displays twitching motility when adherent to ME180 cells (indicative of functional retractile pili) and does not shed fibres into 
A

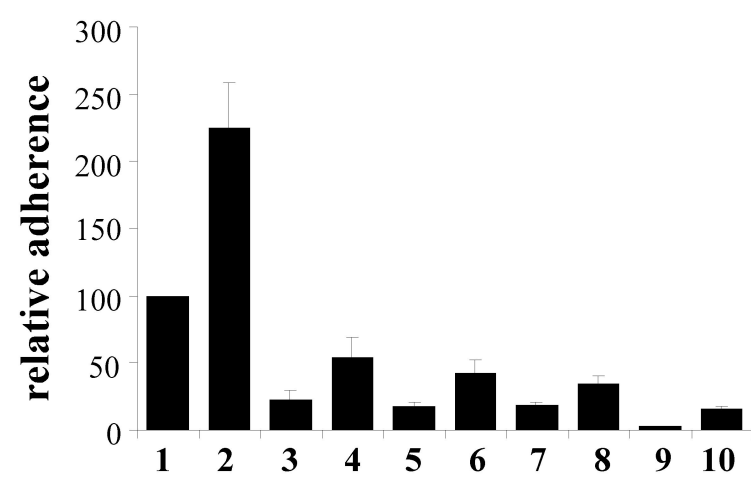

B

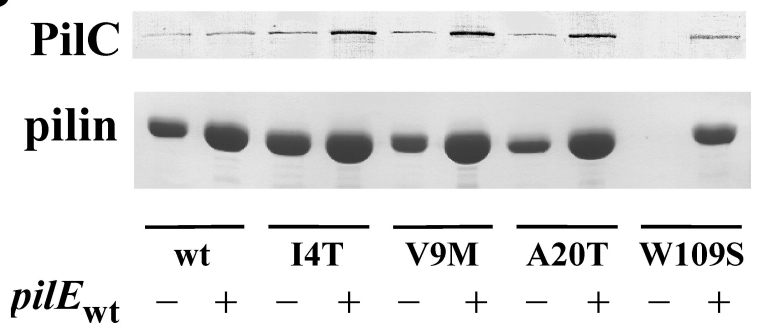

Fig. 6. Missense PilE polypeptides have dominant-negative effects on gonococcal adherence for human epithelial cells. Strains simultaneously expressing both wild-type and altered pilE alleles were examined for adherence to ME-180 cells (A, top) and levels of Tfp expression. (B, bottom).

A. Quantification of gonococcal adherence assessed by recovery of viable colony-forming units (cfu). The results are the average of three independent experiments, with error bars indicating the standard deviations, and are presented as a ratio of the values of the mutants versus the wild-type control in percentages.

B. Coomassie blue-stained SDS-PAGE gel showing the relative amounts of pilin in purified Tfp preparations. Amounts of sample loaded were normalized to one another based on total amounts of protein remaining in whole-cell fractions after shear preparation of Tfp. Strains shown are: 1, N400 (wt); 2, GE200 ( pilE, iga::pilE); 3, GE101 ( pilE $_{14 \mathrm{~T}}$ ); 4, GE301 ( pilE $_{14 \mathrm{~T}}$, iga::pilE); 5, GE102 (pil| $\mathrm{V}_{\mathrm{VMM}}$ ); 6, GE302 (pilE $E_{\mathrm{V} 9 \mathrm{M}}$, iga::pilE); 7, GE103 (pilE $\mathrm{A}_{\mathrm{A} 20 \mathrm{~T}}$ ); 8, GE303 (pilE A20T,

iga::pilE); 9, GE104 (pilE $\left.\mathrm{W}_{\mathrm{W} 109 \mathrm{~S}}\right) ; 10, \mathrm{GE} 04$ ( pilE $\mathrm{W}_{\mathrm{W} 109 \mathrm{~s}}$, iga::pilE).

culture supernatants of liquid media more than the wildtype parent (data not shown). In addition, we have recently isolated mutants in which Tfp do not appear to be anchored properly, are grossly defective in adherence and lack the above-mentioned traits (M. Koomey, unpublished results). In summary, the simplest and most consistent correlate of the defects in adherence is the lack of bacterial interactions.

It is relevant to consider what parameters are involved in the mechanism by which Tfp-mediated aggregation promotes net adherence as seen here. One scenario could be that aggregates of gonococci adhere with greater avidity or affinity to the human cell receptor, perhaps because of a more localized clustering and presentation of the PilC adhesin. Alternatively, all infectious units (whether single diplococci or cell aggregates) may have the same adherence propensities. If this were the case, differences in adherence between aggregating and non-aggregating populations would be enhanced under conditions in which the levels of corresponding human cell receptor are limiting. Results from Scheuerpflug et al. (1999) suggest that established epithelial cell lines, such as ME180 used here, have lower densities of accessible PilC receptors relative to primary cells and, as such, we cannot currently differentiate between these two scenarios.

In attempting to understand how the PilE amino acid substitutions found here lead to a piliated but nonaggregating phenotype, they can be examined in the context of the crystallographic structure of pilin and modelled fibre assembly (Parge et al., 1995). The three amino-terminal substitutions map within the hydrophobic, proximal segment of the $\alpha_{1}$ helix of pilin. In the monomerbased fibre model, the $\beta$-sheet carboxy-terminal part of

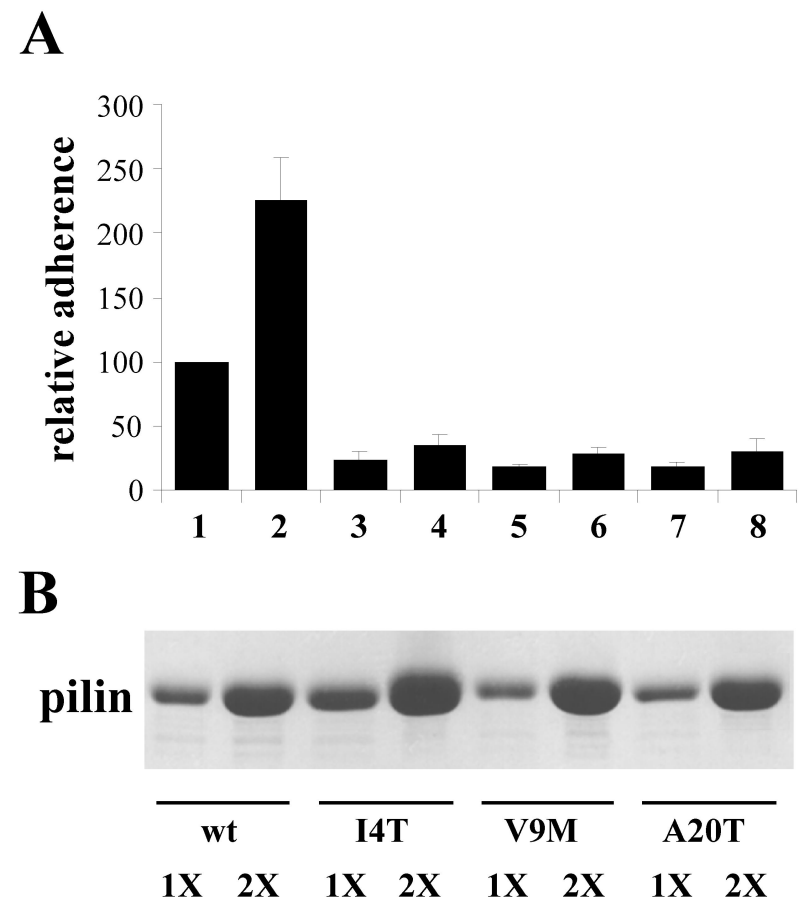

Fig. 7. Quantitative effects of pilE gene dosage on adherence for human epithelial cells. Strains expressing two identical alleles of pilE were examined for adherence to ME180 cells (A, top) and levels of Tfp expression (B, bottom).

A. Quantification of gonococcal adherence assessed by recovery of viable colony-forming units (cfu). The results are the average of three independent experiments, with error bars indicating the standard deviations, and are presented as a ratio of the values of the mutants versus the wild-type control in percentages.

B. Coomassie blue-stained SDS-PAGE gel showing the relative amounts of pilin in purified Tfp preparations. Amounts of sample loaded were normalized to one another based on total amounts of protein remaining in whole-cell fractions after shear preparation of $\mathrm{Tfp}$. Strains shown are: 1, N400 (wild type); 2 GE200 (pilE, iga::pilE); 3,

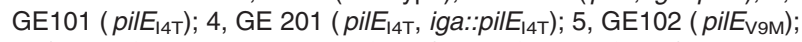

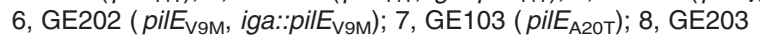
( pilE $_{\mathrm{A} 20 \mathrm{~T}}$, iga::pilE $E_{\mathrm{A} 20 \mathrm{~T}}$ ). 
Table 1. Neisseria gonorrhoeae strains used in this study.

\begin{tabular}{|c|c|c|c|c|c|c|c|}
\hline Strain & $\begin{array}{l}\text { Relevant } \\
\text { genotype }\end{array}$ & Piliation $^{a}$ & $\begin{array}{l}\text { Adherence } \\
\text { pattern }^{b}\end{array}$ & $A A^{c}$ & $\begin{array}{l}\text { Twitching } \\
\text { motility }\end{array}$ & $\begin{array}{l}\text { Transformation } \\
\text { efficiency } \\
(\%)\end{array}$ & Source \\
\hline $\mathrm{N} 400$ & Wild type & + & $L A+D A$ & + & + & 100 & Wolfgang et al. (1998) \\
\hline $\mathrm{GE} 100^{\mathrm{d}}$ & $p i l E_{\mathrm{G}-1 \mathrm{~S}}$ & - & - & - & - & $<0.01$ & This study \\
\hline GE101 & pilE $E_{14 T}$ & + & DA & - & + & 100 & This study \\
\hline GE102 & pilE $E_{\mathrm{V} 9 \mathrm{M}}$ & + & DA & - & + & 100 & This study \\
\hline GE103 & pilE $E_{\mathrm{A} 20 \mathrm{~T}}$ & + & DA & - & + & 100 & This study \\
\hline GE104 & pilE $E_{\mathrm{W} 109 \mathrm{~S}}$ & - & - & - & - & $<0.01$ & This study \\
\hline GE200 & iga:::pil $E_{\mathrm{wt}}$ & ++ & $\mathrm{LA}+\mathrm{DA}$ & + & + & 100 & This study \\
\hline GE201 & pilE $_{14 \mathrm{~T}}$, iga:::pil| $E_{14 \mathrm{~T}}$ & ++ & DA & - & + & 100 & This study \\
\hline GE202 & pilE $_{\mathrm{V} 9 \mathrm{M}}$, iga::pil $\mathrm{E}_{\mathrm{V} 9 \mathrm{M}}$ & ++ & DA & - & + & 100 & This study \\
\hline GE203 & pil $E_{\mathrm{A} 20 \mathrm{~T}}$, iga:: & ++ & DA & - & + & 100 & This study \\
\hline GE301 & pilE $_{14 \mathrm{~T}}$, iga::pilE $E_{\mathrm{wt}}$ & ++ & DA & - & + & 100 & This study \\
\hline GE302 & pilE $_{\mathrm{V} 9 \mathrm{M}}$, iga::pilE $E_{\mathrm{wt}}$ & ++ & DA & - & + & 100 & This study \\
\hline GE303 & pilE $E_{\mathrm{A} 20 \mathrm{~T}}$, iga:: pil $E_{\mathrm{wt}}$ & ++ & DA & - & + & 100 & This study \\
\hline GE304 & pil $_{\mathrm{W} 109 \mathrm{~s}}$, iga:::pil $E_{\mathrm{wt}}$ & + & DA & - & + & 100 & This study \\
\hline GT6 & pilT::mTnerm6 & + & LA & +++ & - & $<0.01$ & Wolfgang et al. (1998) \\
\hline GET101 & pil $_{14 \mathrm{~T}}$, pilT::mTnerm6 & + & LA & +++ & - & $<0.01$ & This study \\
\hline GET102 & pilE $_{\mathrm{V} 9 \mathrm{M}}$, pilT::mTnerm6 & + & LA & +++ & - & $<0.01$ & This study \\
\hline GET103 & pilE $E_{\mathrm{A} 20 \mathrm{~T}}$, pilT::mTnerm6 & + & LA & +++ & - & $<0.01$ & This study \\
\hline GET104 & pil $E_{\mathrm{W} 109 \mathrm{~S}}$, pilT::mTnerm6 & - & - & - & - & $<0.01$ & This study \\
\hline GET304 & $\begin{array}{l}\text { pilE } E_{\mathrm{W} 109 \mathrm{~s}}, \text { iga::pil } E_{\mathrm{wt}}, \\
\text { pilT::mTncm17 }\end{array}$ & + & LA & +++ & - & $<0.01$ & This study \\
\hline
\end{tabular}

a. Relative piliation levels determined by quantitative purification protocol.

b. LA, localized adherence; DA, diffuse adherence.

c. $A A$, autoagglutination.

d. All strains below derived from $\mathrm{N} 400$.

pilin forms a tubular $\beta$-wrap around a core of packed $\alpha_{1}$ helices in a right-handed configuration with five subunits per turn. The two $\alpha_{1}$ helix kinks (resulting from proline at residue 22 and glycine at residue 42) facilitate parallel coiled-coil helix packing with a potential salt bridge from the negatively charged side-chain from glutamate at position 5 in the first subunit to the positively charged amino-terminus of the next subunit. Given the putative critical role of this region in subunit-subunit contacts, the substituted residues may alter helix registration. These alterations occur within the part of the subunits predicted to be buried within the fibre; however, altered helical packing could influence the relative orientation or exposure of positive and negative surface patches, which may contribute to electrostatic fibre-fibre contacts and, thus, lateral aggregation. Altered registration would also be consistent with the dominant-negative activities of the mutated alleles. Previously, studies of strains of $V$. cholerae carrying identical mutations to those isolated here in TсpA, the pilin subunit of the toxin co-regulated pilus, revealed an association between pilus fibre bundling (lateral aggregation), autoagglutination and the capacity to colonize mice intestinally (Chiang et al., 1995). A more recent study using alanine scanning mutagenesis of TcpA also found a strong association of these three properties (Kirn et al., 2000). In some of the non-aggregating mutants carrying amino acid substitutions in the C-terminus, suppressor mutants in which in all three phenotypes were restored were found to carry compensatory amino acid alterations located in the $\mathrm{N}$-terminus. In addition, intragenic suppression of the $t c p A_{\mathrm{V} 20 \mathrm{~T}}$ allele (synonymous with the pil $E_{\mathrm{A} 20 \mathrm{~T}}$ allele described here) occurred by a substitution at P169. The alleviation of all three defects by intragenic suppression could indicate a direct interaction involving these two regions within a single pilin or between individual pilins within the pilus fibre. High-resolution structural studies are required in order to confirm the hypothesis that altered subunit registration leads directly to aberrant fibre morphologies in the N. gonorrhoeae and $V$. cholerae systems.

Differences in human epithelial adherence displayed by piliated $N$. gonorrhoeae and $N$. meningitidis strains have been reported in many studies (Virji and Heckels, 1984; Rudel et al., 1992; Virji et al., 1992; Nassif et al., 1993; Jonsson et al., 1994). The variants examined in these studies express antigenically variant PilE subunits containing multiple residue substitutions within the variable domains of the polypeptide. Given the multiple residue changes found in these variants, it has been difficult if not impossible to relate any particular domain of the pilin subunit to altered adherence capabilities and, in most cases, reduced epithelial cell adherence correlated with a reduction in Tfp expression and the reduced assembly proficiency of the particular pilin. In studies of meningococcal Tfp antigenic variants and adherence (Marceau et al., 1995), the presence of a lysine residue rather than aspartic acid at 
A

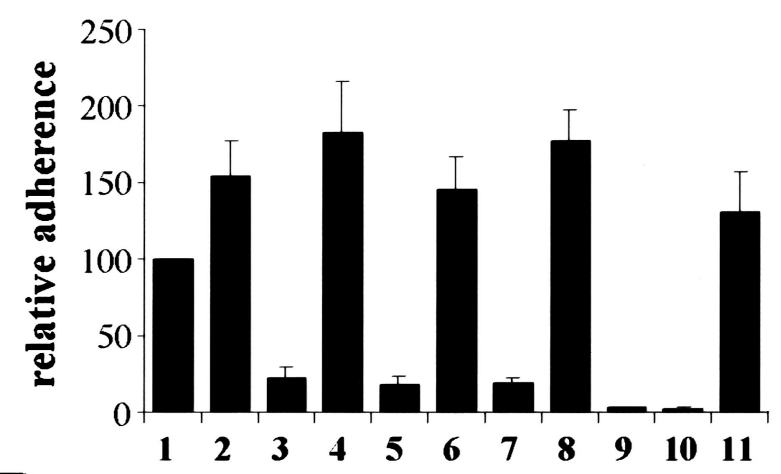

B

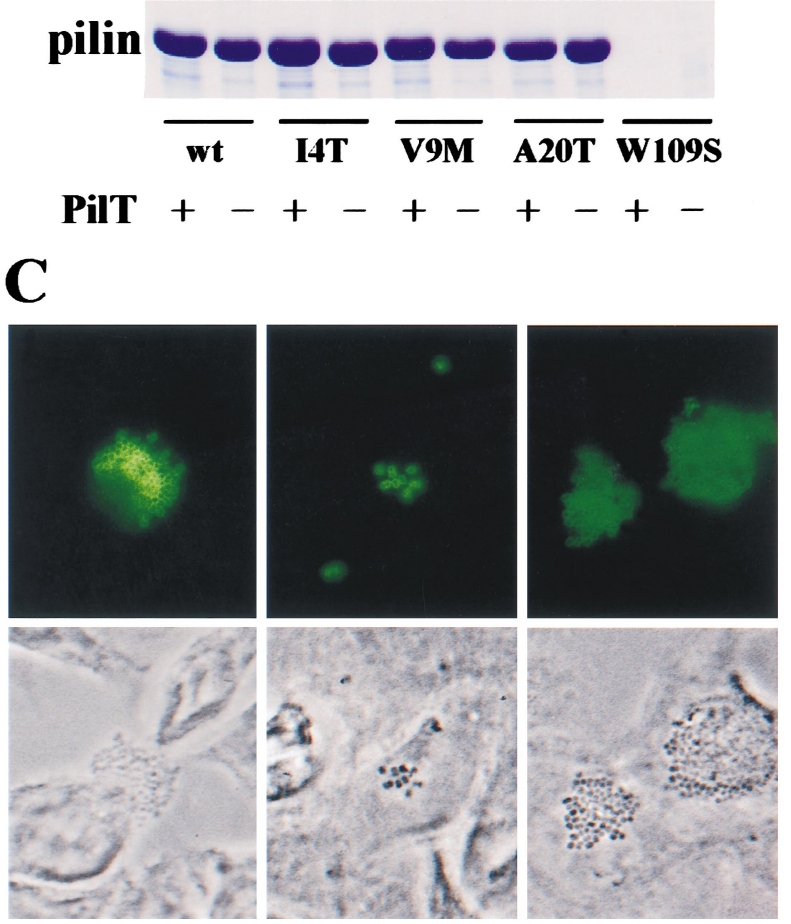

Fig. 8. Inactivation of the pilT twitching motility gene suppresses the defects in aggregation and adherence for human cells of PilE missense mutants.

A. Quantification of gonococcal adherence assessed by recovery of viable colony-forming units (cfu). The results are the average of three independent experiments, with error bars indicating the standard deviations, and are presented as a ratio of the values of the mutants versus the wild-type control in percentages.

B. Coomassie blue-stained SDS-PAGE gel showing the relative amounts of pilin in purified Tfp preparations. Amounts of sample loaded were normalized to one another based on total amounts of protein remaining in whole-cell fractions after shear preparation of Tfp. Strains used are: 1, N400 (wild type); 2, GT6 ( pilT::mTnerm6); 3, GE101 ( pilE $_{14 \mathrm{~T}}$ ); 4, GET101 (pilE $\mathrm{E}_{14 \mathrm{~T}}$, pilT::mTnerm6); 5, GE102

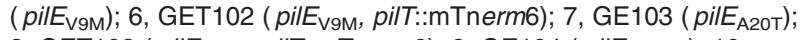
8, GET103 ( pilE $_{\mathrm{A} 20 \mathrm{~T}}$, pilT::mTnerm6); 9, GE104 (pilE $\mathrm{W}_{\mathrm{W} 109 \mathrm{~S}}$ ); 10,

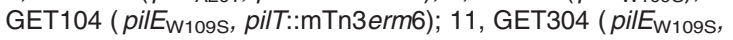
iga::pilE, pilT::mTncm17). Note: strain GET304 ( pilE ${ }_{\mathrm{W} 109 \mathrm{~s}}$, iga::pilE, pilT::mTncm17) is not shown in (B).

C. Microscopic appearance of adherent gonococci detected by phasecontrast imaging (top row) and immunofluorescent labelling using a monoclonal antibody specific for the Por protein (bottom row). Left, N400 (wild type); centre, GE103 ( pilE $E_{\mathrm{A} 20 \mathrm{~T}}$ ); and right, GET103 ( pil $_{\mathrm{A} 20 \mathrm{~T}}$, pilT::mTnerm6). position 140 of PilE was noted in association with high adhesiveness. By constructing strains expressing pilins with either of these residues at position 140, they established a correlation between high adhesiveness and the expression of Tfp fibres in laterally aggregated bundles, which caused the bacteria to clump, and inferred that high adhesiveness was correlated with bacterial interactions. In contrast to these findings and those made in $V$. cholerae, our data fail to indicate any strong association between bundled or laterally aggregated pilus fibres and bacterial aggregation. For example, the A20T mutant has more bundled fibres than the wild-type strain, and the 14T, A20T and W109S heterodiploids all have lateral aggregated fibres in abundance but fail to aggregate. Moreover, even the V9M mutant, which has defective fibre morphology, has some degree of fibre bundling. Furthermore, the suppression of the aggregation defects seen in the context of the pilT mutation does not lead to increased fibre bundling or correction of the fibre morphology defect in the V9M background as seen in TEM (data not shown). Rather, the results here using SEM correlate differences in bacterial interactions with alterations in the organization of Tfp fibres into higher ordered structures that tether cells to one another.

The situation for the dominant-negative activity of the pil $E_{\mathrm{W} 1095}$ allele is obviously different from that of the others, as the pilin product is intrinsically defective in assembly. This residue is part of the conserved pentapeptide LSLWA, which maps between the variable disulphide loop and central $\beta$-sheet regions. The finding that the co-expression of this assembly-defective subunit with a wild-type pilin abolishes aggregation but does not decrease Tfp levels (relative to the strain that expresses only the wild-type pilin) may indicate that the defective subunit titrates out a factor critical to aggregation. Alternatively, we speculate that this altered pilin cannot form fibres on its own but can be incorporated into heterogeneous fibres in the presence of the wild-type pilin. If this were true, purified Tfp from a strain expressing both gene types should contain some W109S pilin but, currently, there are no simple methods for detecting the presence of low amounts of pilin altered only at that residue.

A second potential explanation for the lack of aggregation in both types of mutants stems from observations made in studies of R64 conjugative pili, which is also a type IV pilus. In that system, R64 Tfp are required for mating in liquid cultures and appear to function in that process by promoting cell-cell aggregation (Yoshida et al., 1998). These Tfp fibres appear to consist of predominantly the major subunit PilS and trace amounts of PilV, each of which has characteristics of type IV pilins. PilV is essential for mating and aggregation but not for fibre formation 
wt
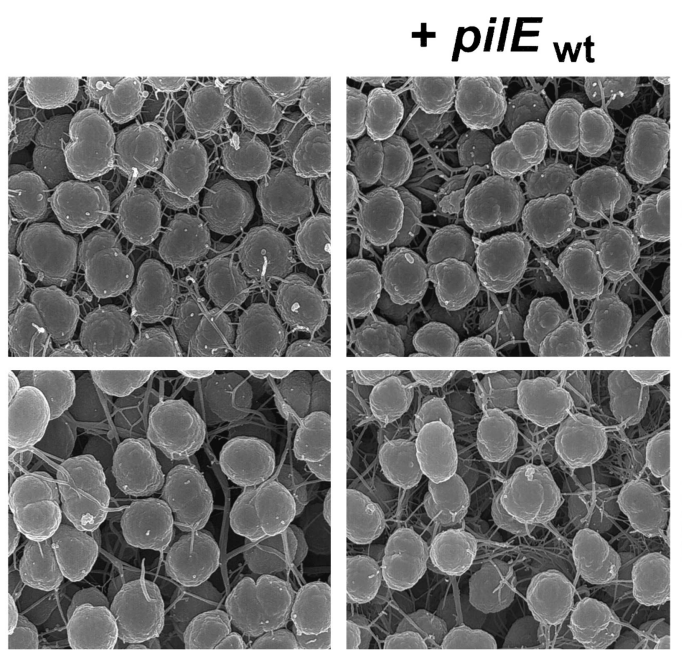

14T

V9M
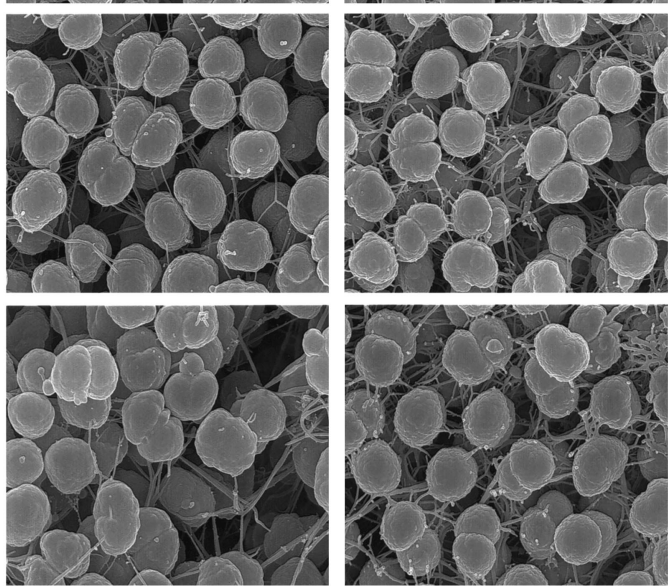

A20T
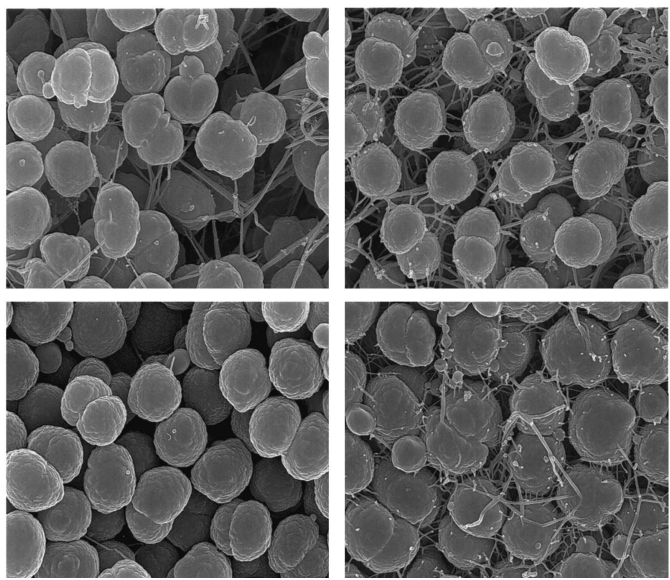
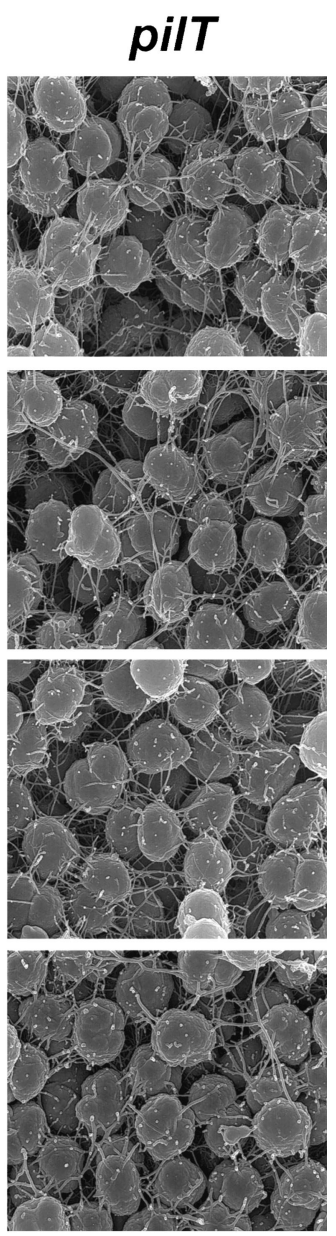

Fig. 9. Missense PilE polypeptides influence filamentous cellular interconnections associated with pilus fibres. Scanning electron micrographs of strains expressing PilE missense polypeptides show qualitative differences in the expression of pilus fibreassociated cellular interconnections. Strains shown in the leftmost column are wt (N400), I4T (GE101), V9M (GE102), A20T (GE103) and W109S (GE104). Centre columns show strains co-expressing the wild-type pilE allele, and strains shown are: wt, GE200 (pilE, iga::pilE); 14T, GE301 ( pil| $E_{14 T}$, iga::pilE); V9M, GE302 ( pil| ${ }_{\mathrm{V} 9 \mathrm{M}}$, iga::pilE); A20T, GE303 ( pilE $E_{\mathrm{A} 20 \mathrm{~T}}$, iga::pilE); and

W109S, GE304 ( pilE $\mathrm{W}_{\mathrm{W} 109 \mathrm{~s}}$, iga:::pilE). Right columns show strains in which the pilT gene has been inactivated by insertion of a transposon. Strains shown are: wt, GT6 (pilT::mTnerm6); I4T, GET101 ( pil| $\mathrm{I}_{\mathrm{I} 4 \mathrm{~T}}$, pilT::mTnerm6); V9M, GET102 ( pil $E_{\mathrm{V} 9 \mathrm{M}}$, pilT::mTnerm6); and A20T, GET103 ( pil $_{\mathrm{A} 20 \mathrm{~T}}$, pilT::mTnerm6). All magnifications are $90000 \times$.

\section{W109S}

by PilS. If an analogous molecule and situation were to exist in $N$. gonorrhoeae, the basis for aggregation in the PilE mutants might reflect the inabilities of those pilins to interact with a PilV-like protein or promote incorporation of a PilV-like protein into the fibre. The gonococcal genome sequence currently contains six additional open reading frames (ORFs) predicted to encode type IV pilin molecules in addition to PilE and the recently characterized ComP protein, which is required specifically for DNA uptake in competence for natural transformation (Wolfgang et al., 1999). The potential contribution to aggregation of the other ORFs is currently under investigation.

It is important to recall that, in all the cases examined here, the aggregation defects are only seen when PilT is present (or, conversely, the defects are suppressed by loss of PilT function), a protein that is essential for pilus retraction (Merz et al., 2000) and twitching motility, but is dispensable for Tfp expression. These results emphasize that a thorough understanding of the molecular basis for multicellular behaviour associated with these organelles requires knowledge of pilin structure, fibre organization and the composition of the tubular cellular interconnections, as well as how PilT exerts its influence on those molecules and structures.

In summary, these studies prove the critical role of residues within the amino-terminus of the $N$. gonorrhoeae pilin subunit in aggregation and their influence on human cell adherence. The three residues altered in the mutants are absolutely conserved in the type IVa family of pilins, and two out of three are conserved in the type IVb family of pilins (Giron et al., 1994). As it is clear that these residues 
are not maintained strictly because they are essential to fibre formation or other Tfp-associated properties, we propose that their conserved nature reflects in part the selective advantages imparted by cell-cell interactions and other characteristics of multicellular behaviour. The proposition that organelle-associated aggregation in itself may be an important colonization factor is also consistent with the observations that Tfp expression in $V$. cholerae (Tamamoto et al., 1998) and in EPEC (Hicks et al., 1998) does not appear to promote direct adherence to primary human intestinal mucosal tissue but is nonetheless critical to colonization at these sites.

\section{Experimental procedures}

\section{Bacterial strains, plasmids and mutations}

Bacterial strains and cloning vectors used in this study are listed in Table 1. Gonococcal strains were propagated on solid Gc media at $37^{\circ} \mathrm{C}$ in $5 \% \mathrm{CO}_{2}$ or in this media lacking agar preincubated overnight in $5 \% \mathrm{CO}_{2}$ (Koomey et al., 1987). All gonococcal strains used were $\mathrm{Opa}^{-}$. E. coli strains and their recombinants were grown at $37^{\circ} \mathrm{C}$ in Luria-Bertani (LB) medium supplemented with the appropriate antibiotics.

The pilE genes from spontaneous gonococcal mutant strains were cloned as a $1.4 \mathrm{~kb}$ Smal fragment in pUC18 as described previously (Zhang et al., 1992).

pUC18 carrying mutated pilin genes was digested with Bsu36l and Bgll. The gel-purified $251 \mathrm{bp}$ Bsu36l-Bgll pilE fragments were then subcloned into corresponding sites in pPilE (Wolfgang et al., 2000) carrying the wild-type pilE allele. Each plasmid clone was verified for altered alleles by sequencing amplified pilE genes using custom-designed pilin primers.

Oligonucleotide-directed site-specific mutagenesis of pPilE was carried out according to the protocol supplied with the Altered Site II in vitro mutagenesis system (Promega). The antisense oligonucleotide primer W109S (5'-pACGCCTG CCGGACAGGGAGAG-3', underlining indicates sites of mutations) was used to change the 109th (number in the mature pilin) codon from TGG to TCC, resulting in a substitution of serine for tryptophan. Underlined nucleotides represent a newly created Hpall restriction site, and bold nucleotides indicate altered ones. Putative mutant clones were sequenced for the entire pilE gene to verify for mutant allele and used for transformation of gonococcal N400 strain. The altered alleles were introduced into the wild-type strain by a non-selective transformation procedure as described previously (Gunn and Stein, 1996).

The pilT knock-out mutations were generated by transforming various strains with plasmid $\mathrm{p} 11 / 2 / 7$ carrying a transposon insertion in the pilT ORF ( pilT::mTnerm6 or pilT::mTncm17) (Wolfgang et al., 1998). Transformants were selected for resistance to erythromycin $\left(8 \mu \mathrm{g} \mathrm{ml}^{-1}\right)$ or chloramphenicol $\left(10 \mu \mathrm{g} \mathrm{ml}^{-1}\right)$ respectively. pilU mutations were introduced into gonococcal strains with p1-49 containing transposon U2 (pilU::mTnerm2) (H.-S. M. Park, M. Wolfgang, and M. Koomey, manuscript submitted). Transformants were obtained by selection on $\mathrm{Gc}_{\mathrm{c}}$ agar plates containing erythromycin $\left(8 \mu \mathrm{g} \mathrm{ml}^{-1}\right)$. Transformants were analysed by SDS-PAGE and immunoblotting with specific serum to verify the absence of PilT protein.

\section{Construction of gonococcal strains carrying a duplication of pilin expression locus}

Wild-type and pilin variant pilE alleles were polymerase chain reaction (PCR) amplified from chromosomal DNA using Taq DNA polymerase (Gibco BRL) and custom-designed primers PilE $5^{\prime}$-Sac and PilE $3^{\prime}$-Sac (\#2) as described previously (Wolfgang et al., 2000). PCR products were digested with $\mathrm{Sacl}$ and cloned into a unique Sacl site located at the $5^{\prime}$ end of the ermC in plgA-ERM. The resulting plasmids were used to transform wild-type and pilin variants. Recombinants were obtained by selection on Gc agar plates containing erythromycin $\left(8 \mu \mathrm{g} \mathrm{ml}^{-1}\right)$.

\section{DNA sequencing and sequence analysis}

Sequencing of pilin genes was performed using purified PCRgenerated double-stranded DNA or gonococcal genomic DNA. Sequences were determined using the ThermoSequenase kit (Amersham) or the Prism ready reaction dyedeoxy terminator cycle sequencing kit (Applied Biosystems) using custom-designed pilin gene oligonucleotide primers. DNA and protein sequence data were compiled and analysed by computer using both the MACVECTOR 6.0 (International Biotechnologies) and the University of Wisconsin Genetics Computer Group (UWGCG) software packages (Devereux et al., 1984).

\section{Characterization of twitching motility and measurement of transformation frequencies}

Twitching motility was assessed by both direct visualization of cells at the periphery of colonies and attached to epithelial cells observed with a microscope as well as by the slide culture method, in which cells are inoculated onto Gc agar slices on microscope slides, covered with a coverslip and visualized under a phase microscope using the $40 \times$ objective (Wolfgang et al., 2000). Competence for natural transformation of gonococcal strains was assessed as described previously using chromosomal DNA from rifampicin- and nalidixic acid-resistant mutants of VD300 (Zhang et al., 1992) as well as plasmid pSY6 DNA carrying a gonococcal gene responsible for low-level nalidixic acid resistance (Stein et al., 1991). Transformants were selected on agar plates containing $10 \mu \mathrm{g} \mathrm{ml}^{-1}$ nalidixic acid or $5 \mu \mathrm{g} \mathrm{ml}^{-1}$ rifampicin for chromosomal DNA and $1 \mu \mathrm{g} \mathrm{ml}^{-1}$ nalidixic acid for plasmid DNA.

\section{Adherence assay}

The adherence assay was performed using ME180 cells, human epidermoid carcinoma, obtained from the American Culture Collection. ME180 cells were maintained in McCoy's $5 \mathrm{~A}$ medium supplemented with $10 \%$ fetal bovine serum (FBS). These epithelial cells were seeded into a 24-well tissue culture plate at a density of $5 \times 10^{5}$ cells on the day before infection. For assays, $2-5 \times 10^{7}$ bacteria in $1 \mathrm{ml}$ of McCoy's 
$5 \mathrm{~A}$ medium supplemented with $1 \%$ FBS (assay medium) were added to each well of the monolayers and incubated at $37^{\circ} \mathrm{C}$ in a $5 \% \mathrm{CO}_{2}$ incubator. After $1 \mathrm{~h}$, non-adherent bacteria were removed by washing five times with assay media. The monolayers and cell-associated bacteria were then recovered by treatment with $0.25 \%$ trypsin for $5 \mathrm{~min}$ at $37^{\circ} \mathrm{C}$. The recovered bacteria were plated on agar after dilution. The number of cell-associated bacteria was determined by the colony-forming units (cfu). Adherence was quantified by determining the ratio of cell-associated cfu to total cfu of the inoculum. Results are presented as the ratio of the adherence of the tested strains to that of the wild-type controls.

\section{Immunofluorescence microscopy}

Immunofluorescence microscopy was performed to visualize directly the binding of gonococci to human epithelial cells. ME180 cells were cultivated in 24-well plates on glass coverslips until confluent and infected with various gonococcal strains by the same method as described in adherence assay. The cells were washed five times with PBS to remove non-adherent bacteria and then fixed with methanol on ice for $5 \mathrm{~min}$. The coverslips were air dried and rinsed again with PBS. Fixed cells on coverslips were incubated with $30 \mu \mathrm{l}$ of fluorescein-labelled mouse monoclonal antibodies specific to gonococcus (Neisseria gonorrhoeae culture confirmation test kit; Syva Microtrak) for $15 \mathrm{~min}$ at $37^{\circ} \mathrm{C}$, according to the manufacturer's specification. The coverslips were rinsed with distilled water and thoroughly air dried before mounting on a slide. Cells were viewed with a Leitz orthoplan microscope.

\section{Electron microscopy}

Electron microscopy samples were prepared on $3.05 \mathrm{~mm}$ Formvar/carbon-coated grids (Tousimis Research). Before use, the grids were discharged in a high vacuum evaporator (Denton model DV-502) to facilitate spreading of both bacteria and stain. Grids were gently touched to individual bacterial colonies grown for $16 \mathrm{~h}$ on a Gc agar plate. The grids were air dried for $10 \mathrm{~min}$, floated on a drop of $0.5 \%$ ammonium molybdate $(\mathrm{pH} 7.0)$ for $30 \mathrm{~s}$ and again air dried. The specimens were examined using a Philips CM-10 transmission electron microscope. For SEM, colonies were grown overnight on $13 \mathrm{~mm}$ GTTP Millipore filters $(0.2 \mu \mathrm{m})$ layered onto $\mathrm{Gc}$ agar plates. Filters were transferred to 24 -well plates containing $1 \mathrm{ml}$ of $2.5 \%(\mathrm{v} / \mathrm{v})$ glutaraldehyde in $0.1 \mathrm{M}$ sodium cacodylate $(\mathrm{pH} 7.2)$ and fixed for $30 \mathrm{~min}$ at room temperature. Samples were post-fixed for $30 \mathrm{~min}$ in $1 \%$ osmium tetroxide in cacodylate buffer. The filters were then washed twice in deionized water, dehydrated in ethanol and critical point dried through carbon dioxide. Dried samples were mounted onto sample stubs, lightly sputter coated with iridium and examined with a Hitachi S-4500 field emission scanning electron microscope operated at $5 \mathrm{kV}$.

\section{SDS-PAGE, immunoblotting and staining}

For the detection of the proteins, whole-cell lysates were subjected to SDS gel electrophoresis and immunoblotting. Protein samples were separated on $12.5 \%$ acrylamide gels and then transferred to Immobilon-PSQ polyvinylidene difluoride (PVDF) membranes (Millipore). Filters were incubated with a rabbit polyclonal pilin-specific antibody GC2-66 (Wolfgang et al., 2000) or PilT-specific antiserum raised in rabbits (H.-S. M. Park, M. Wolfgang, and $M$. Koomey, manuscript submitted). Antigen detection was performed using alkaline phosphate-conjugated goat antirabbit antibodies (Tago) and a colorimetric phosphate substrate. Details of sample preparation, SDS-PAGE and antigen detection have been published previously (Koomey et al., 1991). The pilin from purified pili was detected by Coomassie blue staining of SDS-PAGE gels.

\section{Pilus purification}

Pili from gonococci were purified by the ammonium sulphate procedure as described previously (Wolfgang et al., 2000). Bacterial cells from five heavily streaked Petri dishes were suspended in $10 \mathrm{ml}$ of $0.15 \mathrm{M}$ ethanolamine $(\mathrm{pH} 10.5)$, and vortexed for $60 \mathrm{~s}$. For total protein quantification, $100 \mu \mathrm{l}$ of each cell suspension was saved. Cellular debris was removed by centrifugation at $17000 \mathrm{~g}$ for $15 \mathrm{~min}$ at $4^{\circ} \mathrm{C}$, and the supernatant was used as starting material for the purification of pilus. Pili were precipitated by incubation at room temperature for $10 \mathrm{~min}$ with $1 / 10$ th volume of ammonium sulphate-saturated $0.15 \mathrm{M}$ ethanolamine and collected by centrifugation at $17000 \mathrm{~g}$ for $15 \mathrm{~min}$ at $4^{\circ} \mathrm{C}$. Pilus crystals were washed twice with $0.05 \mathrm{M}$ Tris-buffered saline and resuspended in protein sample buffer for analysis. Protein concentrations were determined by the Bradford method using bovine serum albumin as the protein standard.

\section{Acknowledgements}

This work was supported in part by NIH Public Health service grant Al 27837 (M.K.). M.W. acknowledges support from NIH training grant 2 T32 GM07315.

\section{References}

Anantha, R.P., Stone, K.D., and Donnenberg, M.S. (1998) Role of BfpF, a member of the PilT family of putative nucleotide-binding proteins, in type IV pilus biogenesis and in interactions between enteropathogenic Escherichia coli and host cells. Infect Immun 66: 122-131.

Bergstrom, S., Robbins, K., Koomey, J.M., and Swanson, J. (1986) Piliation control mechanisms in Neisseria gonorrhoeae. Proc Natl Acad Sci USA 83: 3890-3894.

Bieber, D., Ramer, S.W., Wu, C.Y., Murray, W.J., Tobe, T., Fernandez, R., and Schoolnik, G.K. (1998) Type IV pili, transient bacterial aggregates, and virulence of enteropathogenic Escherichia coli. Science 280: 2114-2118.

Caparon, M.G., Stephens, D.S., Olsen, A., and Scott, J.R. (1991) Role of $M$ protein in adherence of group $A$ streptococci. Infect Immun 59: 1811-1817.

Chiang, S.L., Taylor, R.K., Koomey, M., and Mekalanos, J.J. (1995) Single amino acid substitutions in the N-terminus of Vibrio cholerae TcpA affect colonization, autoagglutination, and serum resistance. Mol Microbiol 17: 1133-1142.

Devereux, J., Haeberli, P., and Smithies, O. (1984) A 
comprehensive set of sequence analysis programs for the VAX. Nuc Acids Res 12: 387-395.

Giron, J.A., Levine, M.M., and Kaper, J.B. (1994) Longus: a long pilus ultrastructure produced by human enterotoxigenic Escherichia coli. Mol Microbiol 12: 71-82.

Gunn, J.S., and Stein, D.C. (1996) Use of a non-selective transformation technique to construct a multiply restriction/modification-deficient mutant of Neisseria gonorrhoeae. Mol Gen Genet 251: 509-517.

Henrichsen, J. (1983) Twitching motility. Annu Rev Microbiol 37: 81-93.

Hicks, S., Frankel, G., Kaper, J.B., Dougan, G., and Phillips, A.D. (1998) Role of intimin and bundle-forming pili in enteropathogenic Escherichia coli adhesion to pediatric intestinal tissue in vitro. Infect Immun 66: 1570-1578.

Hultgren, S.J., Abraham, S., Caparon, M., Falk, P., St Geme, J.W.d., and Normark, S. (1993) Pilus and nonpilus bacterial adhesins: assembly and function in cell recognition. Cel/73: 887-901.

Jonsson, A.B., Ilver, D., Falk, P., Pepose, J., and Normark, S. (1994) Sequence changes in the pilus subunit lead to tropism variation of Neisseria gonorrhoeae to human tissue. Mol Microbiol 13: 403-416.

Kallstrom, H., Liszewski, M.K., Atkinson, J.P., and Jonsson, A.B. (1997) Membrane cofactor protein (MCP or CD46) is a cellular pilus receptor for pathogenic Neisseria. Mol Microbiol 25: 639-647.

Kirn, T.J., Lafferty, M.J., Sandoe, C.M., and Taylor, R.K. (2000) Delineation of pilin domains required for bacterial association into microcolonies and intestinal colonization by Vibrio cholerae. Mol Microbiol 35: 896-910.

Koomey, M., Gotschlich, E.C., Robbins, K., Bergstrom, S., and Swanson, J. (1987) Effects of recA mutations on pilus antigenic variation and phase transitions in Neisseria gonorrhoeae. Genetics 117: 391-398.

Koomey, M., Bergstrom, S., Blake, M., and Swanson, J. (1991) Pilin expression and processing in pilus mutants of Neisseria gonorrhoeae: critical role of Gly-1 in assembly. Mol Microbiol 5: 279-287.

Kyte, J., and Doolittle, R.F. (1982) A simple method for displaying the hydropathic character of a protein. J Mol Biol 157: 105-132.

Lessl, M., and Lanka, E. (1994) Common mechanisms in bacterial conjugation and Ti-mediated T-DNA transfer to plant cells. Cell 77: 321-324.

Marceau, M., Beretti, J.L., and Nassif, X. (1995) High adhesiveness of encapsulated Neisseria meningitidis to epithelial cells is associated with the formation of bundles of pili. Mol Microbiol 17: 855-863.

Menozzi, F.D., Boucher, P.E., Riveau, G., Gantiez, C., and Locht, C. (1994) Surface-associated filamentous hemagglutinin induces autoagglutination of Bordetella pertussis. Infect Immun 62: 4261-4269.

Merz, A., So, M., and Sheetz, M.P. (2000) Pilus retraction powers bacterial twitching motility. Nature 407: 98-102.

Nassif, X., Lowy, J., Stenberg, P., O'Gaora, P., Ganji, A., and So, M. (1993) Antigenic variation of pilin regulates adhesion of Neisseria meningitidis to human epithelial cells. Mol Microbiol 8: 719-725.

Ojanen-Reuhs, T., Kalkkinen, N., Westerlund-Wikstrom, B., van Doorn, J., Haahtela, K., Nurmiaho-Lassila, E.L., et al.
(1997) Characterization of the fimA gene encoding bundleforming fimbriae of the plant pathogen Xanthomonas campestris pv. vesicatoria. J Bacteriol 179: 1280-1290.

Ottow, J.C. (1975) Ecology, physiology, and genetics of fimbriae and pili. Annu Rev Microbiol 29: 79-108.

Parge, H.E., Forest, K.T., Hickey, M.J., Christensen, D.A., Getzoff, E.D., and Tainer, J.A. (1995) Structure of the fibreforming protein pilin at 2.6 A resolution. Nature 378: 32-38.

Pratt, L.A., and Kolter, R. (1998) Genetic analysis of Escherichia coli biofilm formation: roles of flagella, motility, chemotaxis and type I pili. Mol Microbiol 30: 285-293.

Rudel, T., van Putten, J.P., Gibbs, C.P., Haas, R., and Meyer, T.F. (1992) Interaction of two variable proteins (PilE and PilC) required for pilus-mediated adherence of Neisseria gonorrhoeae to human epithelial cells. Mol Microbiol 6: 3439-3450.

Scheuerpflug, I., Rudel, T., Ryll, R., Pandit, J., and Meyer, T.F. (1999) Roles of PilC and PilE proteins in pilusmediated adherence of Neisseria gonorrhoeae and Neisseria meningitidis to human erythrocytes and endothelial and epithelial cells. Infect Immun 67: 834-843.

Stein, D.C., Danaher, R.J., and Cook, T.M. (1991) Characterization of a gyrB mutation responsible for low-level nalidixic acid resistance in Neisseria gonorrhoeae. Antimicrob Agents Chemother 35: 622-626.

Swanson, J. (1978) Studies on gonococcus infection XII. Colony color and opacity variants of gonococci. Infect Immun 19: 320-331.

Tamamoto, T., Nakashima, K., Nakasone, N., Honma, Y., Higa, N., and Yamashiro, T. (1998) Adhesive property of toxin-coregulated pilus of Vibrio cholerae 01. Microbiol Immunol 42: 41-45.

Tamm, A., Tarkkanen, A.M., Korhonen, T.K., Kuusela, P., Toivanen, P., and Skurnik, M. (1993) Hydrophobic domains affect the collagen-binding specificity and surface polymerization as well as the virulence potential of the YadA protein of Yersinia enterocolitica. Mol Microbiol 10: 995-1011.

Taylor, R.K., Miller, V.L., Furlong, D.B., and Mekalanos, J.J. (1987) Use of phoA gene fusions to identify a pilus colonization factor coordinately regulated with cholera toxin. Proc Natl Acad Sci USA 84: 2833-2837.

Thankavel, K., Shah, A.H., Cohen, M.S., Ikeda, T., Lorenz, R.G., Curtiss, R., III, and Abraham, S.N. (1999) Molecular basis for the enterocyte tropism exhibited by Salmonella typhimurium type 1 fimbriae. J Biol Chem 274: 5797-5809.

Todd, W.J., Wray, G.P., and Hitchcock, P.J. (1984) Arrangement of pili in colonies of Neisseria gonorrhoeae. $J$ Bacteriol 159: 312-320.

Virji, M., and Heckels, J.E. (1984) The role of common and type-specific pilus antigenic domains in adhesion and virulence of gonococci for human epithelial cells. J Gen Microbiol 130: 1089-1095.

Virji, M., Alexandrescu, C., Ferguson, D.J., Saunders, J.R., and Moxon, E.R. (1992) Variations in the expression of pili: the effect on adherence of Neisseria meningitidis to human epithelial and endothelial cells. Mol Microbiol 6: 1271-11279.

Vuopio-Varkila, J., and Schoolnik, G.K. (1991) Localized adherence by enteropathogenic Escherichia coli is an 
inducible phenotype associated with the expression of new outer membrane proteins. J Exp Med 174: 1167-1177.

Whitchurch, C.B., Hobbs, M., Livingston, S.P., Krishnapillai, V., and Mattick, J.S. (1991) Characterisation of a Pseudomonas aeruginosa twitching motility gene and evidence for a specialised protein export system widespread in eubacteria. Gene 101: 33-44.

Wolfgang, M., Lauer, P., Park, H.S., Brossay, L., Hebert, J., and Koomey, M. (1998) PilT mutations lead to simultaneous defects in competence for natural transformation and twitching motility in piliated Neisseria gonorrhoeae. Mol Microbiol 29: 321-330.

Wolfgang, M., van Putten, J.P., Hayes, S.F., and Koomey, M. (1999) The comP locus of Neisseria gonorrhoeae encodes a type IV prepilin that is dispensable for pilus biogenesis but essential for natural transformation. Mol Microbiol 31: 1345-1357.
Wolfgang, M., van Putten, J.P., Hayes, S.F., Dorward, D., and Koomey, M. (2000) Components and dynamics of fiber formation define a ubiquitous biogenesis pathway for bacterial pili. EMBO J 19: 6408-6418.

Wu, S., Wu, J., and Kaiser, D. (1997) The Myxococcus xanthus pilT locus is required for social gliding motility although pili are still produced. Mol Microbiol 23: 109-121.

Yoshida, T., Furuya, N., Ishikura, M., Isobe, T., HainoFukushima, K., Ogawa, T., and Komano, T. (1998) Purification and characterization of thin pili of Incl1 plasmids Collb-P9 and R64: formation of PilV-specific cell aggregates by type IV pili. J Bacteriol 180: 2842-2848.

Zhang, Q.Y., DeRyckere, D., Lauer, P., and Koomey, M. (1992) Gene conversion in Neisseria gonorrhoeae: evidence for its role in pilus antigenic variation. Proc Natl Acad Sci USA 89: 5366-5370. 